\section{Contra-ataque ao Império}

Luiz Alberto Moniz BANDEIRA. Formação do Império americano. Rio de Janeiro, Civilização Brasileira, 2005. 84 páginas.

\section{André Roberto Martin}

Sem dúvida hoje um dos principais historiadores brasileiros, Luiz Alberto de Vianna Moniz Bandeira é autor de vasta obra, concentrada principalmente na subárea formada pela intersecção entre a sociologia histórica e a história das relações internacionais. Especialista na diplomacia triangular entre Brasil-Estados Unidos e Hispanoamérica, Moniz Bandeira é um intelectual que também tem primado pela coerência no esforço de fazer convergir a interpretação do historiador com a ação prática do homem político. Diante dessas referências, não há como deixar passar em branco seu mais recente livro, em que examina, com minúcia, e amparado por abundante documentação, pouco mais de um século de história contemporânea; século que resumidamente poderíamos definir como sendo "o século americano".

De fato o ano de 1895 assinala a passagem dos Estados Unidos à condição de primeira potência industrial do planeta (ver p. 42), posição que ainda ocupa com folga neste início de século XXI. Demorou apenas três anos para que esse poderio industrial se exercitasse belicamente contra uma potência colonial em franca decadência - a Espanha -, nascendo aí a política exterior de tipo "imperial" que tem sido a marca da diplomacia norte-americana desde então, ao menos segundo o ângulo do observador médio latino-americano, uma vez que foi justamente o subcontinente a primeira área a experimentar a força desse "imperialismo", já prenunciado, aliás, pela "doutrina Monroe". Como essa potência regional, relativamente periférica, transformou-se na potência hegemônica dos dias que correm no espaço de apenas um século é o que constitui o objeto central desta obra, cujo subtítulo, bastante eloqüente, é "da guerra contra a Espanha à guerra contra o Iraque".

Ao longo de quase oitocentas páginas, Moniz Bandeira discorre sobre uma infinidade de episódios, que vão desde o pacto Molotov-Ribbentrop, até o combate contra a "narcoguerrilha" colombiana; da weltpolitik de Bismarck, à intervenção da Otan em Kosovo; da insurgência palestina na Jordânia (o setembro negro), à nova política econômica (NEP) de Lênin. Trata-se realmente de um volume de informações considerável, difícil até de ser assimilado, mas bastante útil para um leitor ainda em formação. Por outro lado, para alguém com maior bagagem, poderá talvez parecer algo excessivo o uso de tantas notas a cada capítulo, bem como um pouco dispersivo o recurso à utilização de uma série de exemplos relacionados a processos cuja dinâmica não guarda, afinal, relação causal direta com o "intervencionismo" norteamericano. Como os capítulos se organizam por ordem cronológica e não temática, e o autor procura ressaltar antes as linhas de continuidade que de ruptura, ao leitor cabem duas alternativas: ou lê seletivamente o que lhe interessa, baseado na boa descrição de conteúdo exposta no índice, ou percorre a obra de fio a pavio, num inegável exercício de resistência. Não que o texto de Moniz Bandeira seja enfadonho, muito pelo contrário. O estilo do autor é vivo, provocador, sabendo combinar clareza com profundidade, firmeza de opinião com rigor no uso das fontes, o que apenas reafirma a reputação de bom professor, aquele capaz de compreender as exigências e as necessidades de seus alunos, motivando-os para o aprofundamento dos estudos de sua matéria. Uma vez, porém, que o leque de questões trabalhadas é muito amplo, o risco de discordâncias de interpretação também é alto, e só à guisa de exemplo mencionemos a imagem inusitada pintada por Moniz Bandeira a respeito do presidente Franklin Delano Roosevelt, sempre tido como um liberal humanista e progressista, em contraste com o truculento Harry Truman que o sucedeu, e que notabilizou-se por haver ordenado o bombardeio atômico das cidades japonesas de Hiroshima e Nagasaki. Roosevelt, considerado por Hitler como "o candidato do mundo judeu", é descrito por Moniz Bandeira como um líder ardiloso e belicista, que preparou com bastante antecedência a entrada dos Estados Unidos na guerra, bem como alinhavou a futura ordem mundial baseado no pressuposto da aniquilação total da Alemanha, nação que, segundo o autor, ele odiava de longa data, e pretendia ver reconduzida tecnologicamente 
à era feudal. Assim, o "terrorismo aéreo" perpetrado contra a população civil da Alemanha, num momento em que a Wermacht já se encontrava tecnicamente batida, assemelha-se à decisão de Truman sobre o ataque nuclear contra o Japão. As "razões de Estado" no caso, antes de terem sido ditadas pelo patriotismo contido na premissa de se "pouparem vidas americanas", refletiriam na verdade o desejo dos monopólios industriais estadunidenses de não quererem vir a competir com seus equivalentes japoneses ou alemães no imediato pós-guerra.

Não é que Moniz Bandeira pretenda com isso reabilitar o nazi-fascismo a partir de uma inusitada "história dos vencidos", mas uma vez que o autor se exime de um posicionamento mais claro do ponto de vista "ético" ou "ideológico" quanto a este aspecto, não deixa de passar a impressão de que, para ele, os alemães teriam sido antes vítimas do que protagonistas da história, ao longo da segunda guerra mundial. Seu empenho, em grande medida justificável, de contrapor-se à satanização do povo alemão empreendida pela propaganda liberal do período fica explícito quando, no início desse mesmo capítulo (7), ao reproduzir uma frase de Raymond Aron, lembra que os Estados Unidos foram responsáveis, ao menos em parte, pelo desencadeamento da dupla guerra no Atlântico e no Pacífico (p. 131). Tudo isso revela como é difícil se adotar um ponto de vista "científico" quando o assunto trata das relações internacionais, ou mais precisamente, a história política mundial, uma vez que a neutralidade aqui é impossível. O autor não esconde, por outro lado, sua admiração pela Alemanha como país, o que em si mesmo não parece merecedor de maiores reservas evidentemente. Ele é um dos poucos historiadores patrícios que tem pleno acesso à língua alemã, e já produziu alguns estudos importantes sobre o desenvolvimento histórico da Alemanha, desde os seus primórdios até a recente reunificação do Estado germânico. Se por um lado isso the valeu a comenda da Ordem do Mérito desse país e a alcunha de praeceptor germaniae no meio acadêmico brasileiro, por outro the tem rendido muita dor de cabeça com leitores apressados que não hesitam em ver no filogermanismo do autor um equivalente do anti-semitismo. Esse tipo de crítica, de indisfarçável sabor maniqueísta, não deve evidentemente ser levado muito a sério. Mas há que se reconhecer o embaraço representado por uma postura que, analiticamente, se apóia na convicção de que "os fatos falam por si", com outra, que dá sentido ao conjunto da obra, em que o autor declaradamente "toma partido". A tentativa de combinar "isenção no exame do passado" e "engajamento ante as exigências políticas do presente" não se sustenta por muito tempo, desde que se examine minuciosamente qualquer fato "do passado", simplesmente porque nele estão contidas inúmeras projeções sobre o futuro, o que revela inapelavelmente as preferências do autor sobre qual delas ele considera a mais perfeita "profecia realizada".

Esse parece ser o ponto crítico desta obra. Ao selecionar frases ditas pelos principais atores dos fatos que se está narrando, chega-se sempre a algum juízo de valor. Além disso, os protagonistas da política mundial sempre possuem algum nível de elaboração teórica, e sempre há, além disso, os "hábeis conselheiros do Rei", tomados modernamente como uma comunidade acadêmica bem definida - a dos "cientistas políticos". Como não considerar controversas, portanto, as teses de Moniz Bandeira, quando este apresenta Kautsky, Trotsky e Hitler como teóricos "realistas", que teriam acertado em suas previsões, em contraste com Lênin, Roosevelt e Stálin, que teriam justamente falhado por basearem suas projeções em concepções "idealistas"?

Das três antinomias apresentadas, a que opõe Lênin a Kautsky durante a realização da Segunda Internacional é a que constrói todo o arcabouço teórico da obra, intencionalmente voltada para a defesa da tese de que o pensador austríaco, pupilo de Engels, estava certo ao prever a emergência do "ultra-imperialismo", ao passo que o líder da revolução bolchevique estaria completamente equivocado ao presumir que o imperialismo se converteria na "ante-sala" do socialismo. Partindo da premissa de que o "Império americano" é o ponto de chegada da globalização iniciada com as grandes navegações (p. 29), Moniz Bandeira propõe ir à gênese desse processo, para o que lhe parece conveniente considerar toda a experiência do "socialismo real" uma espécie de "desvio histórico". Assim, a grande antevisão seria a de Kautsky, e o Império americano, a concreti- 
zação do ultra-imperialismo previsto por este. A conclusão soa bastante lógica, mas será que não estaríamos aqui diante de uma tautologia? O Império americano aparece como a manifestação da essência do ultra-imperialismo, e o ultra-imperialismo, por sua vez, manifesta-se como fenômeno, a partir da existência do Império americano. Como data de referência do surgimento de ambos, o ano de 1945. Mas então o ultra-imperialismo e a Guerra Fria seriam categorias equivalentes?

Ademais, se Lênin errou ao classificar o imperialismo como "o capitalismo em decomposição", o "ultra-imperialismo" deveria ser visto, em contrapartida, como um "capitalismo regenerado", e conseqüentemente não poderia conduzir o Império americano para uma ditadura militarista, possibilidade que o autor considera muito próxima de se concretizar, desde que foi editado o USA Patriot Act. Cada teoria é verdade, deve ser avaliada em sua relevância cognitiva a partir do critério da prática, mas a prática deve também ser bem contextualizada historicamente, pois só assim poderemos escolher a teoria que, no embate teórico-político concreto, se revelou a mais eficaz para compreender e transformar a realidade do momento. Vale lembrar nessa direção que Lênin radicalizou suas críticas a Kautsky exatamente porque este abrandara em demasia sua oposição ao capitalismo, ao identificar no ultraimperialismo a solução para a anarquia da produção e a competição entre burguesias nacionais, tendências que, segundo Lênin, levariam inevitavelmente à guerra. O restante da história é bem conhecido, o que nos leva à conclusão de que, na sua circunstância, o homem Lênin acertou.

Permanece outrossim inteiramente aberta a questão sobre a existência ou não de outros imperialismos na cena mundial do presente, já que um só Império estaria reinando, ou pelo menos apenas um imperialismo mereceu investigação... E também o tema do socialismo não é enfrentado, se ele não seria mais necessário ou possível, e se não haveria acertos a resgatar da experiência soviética. Como se vê, trata-se de discordâncias doutrinárias que, evidentemente, estão longe de pretender invalidar a obra em seu conjunto. Muito ao contrário, há que se assinalar que o desvendamento da trama que suscitou a Doutrina Bush representa um dos pontos altos do livro, e o rigor de sua análise política é capaz de convencer até os mais crédulos de que o planeta, mais uma vez, se encontra à deriva como uma "nau dos insensatos". Reitere-se ainda que como manual de consulta trata-se de documento de inestimável valor, bem como pela sistematização e interpretação original de numerosos acontecimentos, merece leitura e discussão cuidadosa. Aqui a idéia foi oferecer uma visão de conjunto da obra, e debater alguns pontos filtrados pelas lentes de um pensamento geopolítico ainda em formação.

Duas questões nessa direção ainda mereceriam ser aprofundadas. A primeira, de natureza metodológica, diz respeito à validade da analogia histórica na explicação de contextos geopolíticos em permanente mutação; a segunda, de teoria política, indaga sobre a verdadeira força e fraqueza do Império americano na atualidade, e o que se pode esperar dele no futuro imediato. Em suma, trata-se de verificar até que ponto o "Império americano" possui uma existência histórica concreta, e até que ponto não constitui apenas um artifício do intelecto, um "constructo lógico". Indo diretamente para o foco da primeira questão, Eliot Cohen já havia notado que os historiadores geralmente objetam as comparações, pois estão preocupados sobretudo em descobrir as singularidades, a excepcionalidade das circunstâncias. Para os políticos e formuladores de política, entretanto, a analogia histórica tem servido como argumento de legitimação, qualquer que seja a atitude tomada. Moniz Bandeira trafega bem pelos dois campos. Quanto aos geopolíticos desse ponto de vista, vale dizer que costumam acompanhar os historiadores, pois a geografia do poder mundial atual é sempre seu ponto de partida, mas, como bem demonstrou MacKinder, podem vir a utilizarse também da analogia histórica, e com bons resultados, desde que atentem para as diferenças de escala geográfica dos fenômenos, bem como para as variações no padrão tecnológico dominante, o que os aproxima, por sua vez, dos cientistas políticos.

Cabe ressaltar, nesse sentido, mais uma vez a tese central de Moniz Bandeira, pois para ele hoje as potências industriais teriam se unido em forma de cartel, comprovando-se assim a tese de Kautsky, de 1914 (pp. 765-766). Mas na ONU e na OMC, por exemplo, a diplomacia estadunidense 
tem colhido seguidas derrotas, e mesmo no G-8, e na própria Otan, não é mais Washington a referência solitária que costumava ser em tempos de Guerra Fria. Diga-se de passagem, após o tiroteio verbal recente entre o vice-presidente norte-americano Dick Cheney e o presidente russo Wladimyr Putin, muitos analistas viram reviver aquela atmosfera pesada das relações russo-americanas dos anos de 1950. Cabe portanto ponderar entre um cenário em que o imperialismo dos Estados Unidos dominará com mais intensidade o panorama político mundial, mas o fará por um período menor, e gerando em seguida uma profunda crise, e outro no qual a hegemonia norte-americana será exercida com menor intensidade nos próximos anos, mas se mostrará porém possuidora de maior fôlego, levando-nos a um longo período de crise administrada. Há ainda, evidentemente, os partidários da permanência do atual status quo, aliás a quase unanimidade dos schollars de língua inglesa, sejam liberais sejam neocons.

Para este último grupo, a despeito da diferença interna entre o idealismo dos democratas e o realismo dos republicanos, hoje sem dúvida o mais poderoso e influente no campo da ciência política, ou das relações internacionais, o uso do substantivo "império" é inclusive considerado um equívoco, um anacronismo, pois, embora alguns dos problemas que os Estados Unidos hoje enfrentam já tivessem surgido em Roma, ou na época da Rainha Vitória, só agora existiria de fato uma única superpotência incontestável, universal, uma "hiperpotência", respaldada por um núcleo geohistórico de dimensões continentais e não apenas um arquipélago ou uma cidade-Estado. Desse ponto de vista, não há dúvida de que Formação do Império americano parecerá entediante, uma vez que para Moniz Bandeira a questão sobre se os Estados Unidos são hoje efetivamente ou não um "Império" não se reduz a uma querela semântica. Muito ao contrário, para ele a opção entre império ou república apresenta-se como crucial neste momento, pois tem o condão de decidir os destinos do mundo inteiro, não apenas em relação à grande nação norte americana. Se a pátria de Jefferson e Paine um dia pôde definir-se, efetivamente, de forma orgulhosa e revolucionária como um empire of liberty, não há como recusar o fato de que hoje, pretensamente legitimado pelos atentados de 11 de setembro, o governo da Casa Branca pretenda impor, conservadoramente, sua liberty of empire sobre o restante do mundo (p. 792). Assim, em contraponto a Antonio Neri e Michael Hardt, para Moniz Bandeira a palavra império representa antes de tudo uma categoria da ciência política e não da economia política. Depois de muita reflexão, e sem condições de estender-me mais, tendo a ficar ao lado do eminente professor baiano. Mas ainda não consegui decidir sobre onde devo, afinal, depositar este seu volume: na estante de história ou de política? Com a palavra o leitor.

\section{ANDRÉ ROBERTO MARTIN é professor no Departamento de Geografia da Faculdade de Letras e Ciências Humanas da USP.}

